\title{
Nerve fibre refractory period in patients treated with rubidium and lithium
}

\author{
R. P. B E T TS, C. PA S C H A L IS, J.A. J A R R A T T, \\ A N D F.A. JE N NER \\ From Sheffield University and Area Health Authority $(T)$, Sub-Regional Department of Medical \\ Physics, Department of Clinical Neurophysiology, Fulwood Annexe, and MRC Unit for Metabolic \\ Studies in Psychiatry, Middlewood Hospital, Sheffield
}

SUMMARY Nerve fibre refractory period distributions have been measured on the median nerves of six manic-depressive patients controlled with lithium carbonate, three chronic patients (two manic-depressives and one catatonic schizophrenic) controlled with rubidium chloride, and eight normal volunteers. Rubidium prolonged the refractory periods of all nerve fibres while lithium increased only the longer refractory periods.

Several studies show that some neurochemical and behavioural actions of rubidium are the opposite of those of lithium (Schildkraut et al., 1967; Meltzer et al., 1969; Carroll and Sharp, 1971; Stolk et al., 1971; Fieve et al., 1973). Except for a report which shows that rubidium produces a pronounced activation of the EEG (Meltzer and Fieve, 1975), there seem to be few electrophysiological studies of the effects of this ion on man.

During the treatment of manic-depressive patients with rubidium (Paschalis et al., 1978), we have had an opportunity to look at its effect on nerve refractory period distributions.

\section{Patients and methods}

For ethical reasons rubidium can only be given at present to severely disturbed patients who have already had most conventional treatments. Hence the following patients were selected.

JR is a chronic hospital patient with a marked cycle of affective disorder over 14 years. Although she has not had fits for the last three years she has been taking phenobarbitone $(30 \mathrm{mg}$ three times a day) for several years. This was maintained throughout the studies. The other patients received no drugs other than rubidium or lithium.

MC is a chronic hospital patient with a 16 year history of severe manic-depressive illness. Over the last seven years she has had a fairly regular mood

Address for reprint requests: Professor F. A. Jenner, Hallamshire Hospital, Sheffield S10.

Accepted 1 May 1978 cycle lasting approximately seven to eight weeks.

FM is a chronic hospital patient with a 25 year history of periodic catatonic schizophrenia.

These patients had not responded to lithium therapy. Nevertheless, they were compared with six otherwise similar manic-depressive patients controlled by lithium carbonate and eight normal volunteers.

The measurements of nerve fibre refractory period distributions were performed on the three patients given rubidium chloride, the six manicdepressive patients who were controlled on lithium carbonate, and the eight normal volunteers. Two of the patients treated with rubidium were investigated before and during therapy (MC and FM).

The technique of measuring the nerve refractory period distribution has been described by Betts et al. (1976). Alternate twin and single stimuli were applied at a single point over the median nerve at the wrist, and monopolar recordings made of the nerve action potentials at the elbow. Lead foil surface electrodes were used throughout. The stimuli were of 100 microseconds duration and the twin pulse interval was varied from $0-10 \mathrm{~ms}$. The stimuli were applied at a rate of one per second and were delivered from the same source to ensure pulses of identical shape and size. The nerve action potentials were amplified through a Medelec AA6 differential amplifier, averaged on a Medelec AVM6 averager and a hard copy was taken on a Medelec fibre optic recorder. The subjects lay supine on a couch and the measurements were taken in a warm room (approximate 
temperature $18^{\circ} \mathrm{C}$ to $22^{\circ} \mathrm{C}$ ). Unfortunately, facilities for strict temperature control were not available. However, since the pretreatment results for the three patients given rubidium were well with the normal range establshied for the eight control subjects, the assumption that slight fluctuations in ambient temperature could be ignored seemed justified.

\section{Results}

The Figure shows the mean tracing of the normal results, a typical result from the lithium studies, and the results from patient MC before and during rubidium administration. The refractory periods in all patients receiving rubidium were significantly prolonged compared to the control group (Table). In each case, there was also a significant difference $(P<0.01)$ between the results obtained before and during rubidium treatment (two-way analysis of variance). The patients receiving lithium also showed increased refractory periods but the changes only attained statistical significance for pulse intervals of $2.25 \mathrm{~ms}$ and above (Table and Figure).

\section{Discussion}

Animal studies have shown that replacement of intracellular potassium by rubidium produces a marked decrease in the outward current and a slight decrease in the inward current associated

Table Nerve fibre refractory period results from eight normal subjects, six manic-depressive patients receiving lithium treatment, and three manic-depressive patients loaded with rubidium chloride

\begin{tabular}{|c|c|c|c|c|c|c|}
\hline \multirow[t]{2}{*}{ Subjects } & \multirow[t]{2}{*}{$\begin{array}{l}\text { Age } \\
\text { (yr) }\end{array}$} & \multirow{2}{*}{$\begin{array}{l}\text { Minimum } \\
\text { refractory } \\
\text { period } \\
\text { (ms }\end{array}$} & \multicolumn{3}{|c|}{$\begin{array}{l}\text { Normalised amplitudes of second nerve } \\
\text { action potential }(\% \text { of max.) for twin } \\
\text { pulse intervals of }\end{array}$} & \multirow{2}{*}{$\begin{array}{l}\text { Maximum } \\
\text { refractory } \\
\text { period } \\
\text { ms }\end{array}$} \\
\hline & & & $1.25 \mathrm{~ms}$ & $2.25 \mathrm{~ms}$ & $2.75 \mathrm{~ms}$ & \\
\hline Normal & $\begin{array}{r}20 \\
25 \\
25 \\
7 \\
23 \\
25 \\
25 \\
36\end{array}$ & $\begin{array}{l}0.70 \\
0.72 \\
0.65 \\
0.67 \\
0.70 \\
0.80 \\
0.87 \\
0.80\end{array}$ & $\begin{array}{l}65.5 \\
54.5 \\
76 \\
64.5 \\
75 \\
37 \\
39 \\
45.5\end{array}$ & $\begin{array}{l}95.5 \\
94.5 \\
99 \\
93 \\
94.7 \\
96 \\
84.5 \\
92.8\end{array}$ & $\begin{array}{c}99 \\
99.2 \\
100 \\
98.5 \\
98 \\
100 \\
95.5 \\
99.5\end{array}$ & $\begin{array}{l}3.0 \\
3.0 \\
2.5 \\
3.0 \\
3.2 \\
2.5 \\
3.2 \\
2.9\end{array}$ \\
\hline $\begin{array}{l}\text { On rubidium } \\
\text { JR } \\
\text { MC } \\
\text { FM }\end{array}$ & $\begin{array}{l}42 \\
43 \\
40\end{array}$ & $\begin{array}{l}0.93 \\
1.05 \\
0.95\end{array}$ & $\begin{array}{r}23.5 \\
7.7 \\
31.5\end{array}$ & $\begin{array}{l}73.5 \\
46.5 \\
87\end{array}$ & $\begin{array}{l}88.7 \\
69.5 \\
96.7\end{array}$ & $\begin{array}{l}3.6 \\
4.0 \\
3.1\end{array}$ \\
\hline $\begin{array}{l}\text { On lithium } \\
\text { MJ } \\
\text { JT } \\
\text { EP } \\
\text { BF } \\
\text { WB } \\
\text { LG } \\
\text { Level of significance for difference from normal given by the } \\
\text { Mann-Whitney statistic }\end{array}$ & $\begin{array}{l}40 \\
58 \\
46 \\
46 \\
73 \\
39 \\
\mathrm{Rb} \\
\mathrm{Li}\end{array}$ & $\begin{array}{l}0.80 \\
0.80 \\
0.90 \\
0.90 \\
0.80 \\
0.73 \\
=0.012 \\
\text { P }<0.02 \\
\text { NS }\end{array}$ & $\begin{array}{l}47 \\
37.5 \\
47 \\
43 \\
50 \\
49.5 \\
=0.012 \\
\text { P }<0.02 \\
\text { NS }\end{array}$ & $\begin{array}{l}85 \\
80.5 \\
86.6 \\
80.5 \\
82.5 \\
78.2 \\
=0.024 \\
P<0.05 \\
=0.002 \\
P<0.01\end{array}$ & $\begin{array}{l}94.5 \\
94.8 \\
94 \\
90.5 \\
88.6 \\
88 \\
=0.024 \\
P<0.05 \\
=0 \\
P<0.01\end{array}$ & $\begin{array}{l}3.5 \\
3.3 \\
3.5 \\
3.5 \\
4.0 \\
3.5 \\
=0.048 \\
P<0.05 \\
=0 \\
P<0.01\end{array}$ \\
\hline
\end{tabular}

NS $=$ not significant.

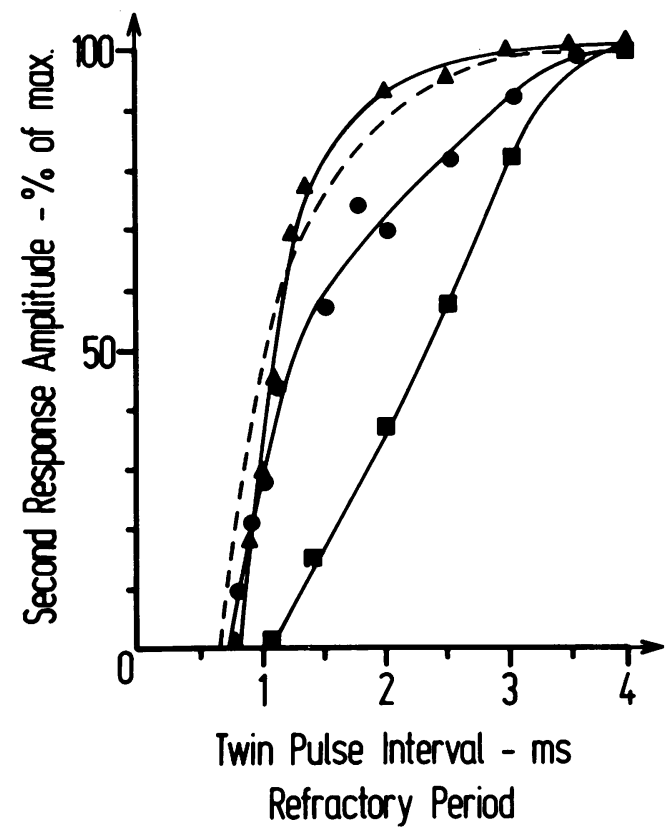

Figure Amplitude of the second response to twin stimuli as a percentage of the maximum response plotted against the interval between the twin pulses. control studies. The results from before $(\mathbf{\Delta})$ and after ( $\square$ ) rubidium in patient $M C$ are also shown as well as a typical study of a patient receiving lithium (๑). The broken line represents the mean value of the 
with the nerve action potential (Chandler and Meves, 1965). These changes would account for delayed restoration of membrane potential and thus for the observation that rubidium prolongs the action potential (Baker et al., 1962). The resting potential is slightly reduced (Baker et al., 1962), but the relation between sodium inactivation and membrane potential is unaffected (Chandler et al., 1965). If rubidium produces similar effects in man it would be expected to cause an increase in the nerve refractory period as shown by our results.

Since lithium does not produce these changes in the form of the nerve action potential in experimental animals the explanation of the mechanism by which its administration to patients is also associated with an increase in the nerve refractory period may be more complex. The larger size of the hydrated lithium ion compared to that of sodium (Conway, 1952), and the diminished efficacy of the sodium pump in the presence of lithium (Keynes and Swan, 1959) may be relevant factors.

Such different mechanisms may also account for our observation that rubidium prolongs the whole range of the nerve refractory periods and to a fairly uniform degree, whereas the changes produced by lithium are largely, if not entirely, confined to the longer refractory period portion of the amplitude-time curve.

We stress that the interpretation of the animal work with these cations must be compared cautiously with the clinical findings, and that with such a small number of patients our observations can be considered only tentative.

We must thank Dr A. A. Angel for correcting our earlier drafts and enthusiasms.

\section{References}

Baker, P. F., Hodgkin, A. L., and Shaw, T. I. (1962). The effects of changes in internal ionic concentra- tions on the electrical properties of perfused giant axons. Journal of Physiology, 164, 355-374.

Betts, R. P., Johnston, D. M., and Brown, B. H. (1976). Nerve fibre velocity and refractory period distribution in nerve trunks. Journal of Neurology, Neurosurgery, and Psychiatry, 39, 694-700.

Carroll, B. L., and Sharp, P. T. (1971). Rubidium and lithium: opposite effects on amine-mediated excitement. Science, 172, 1355-1357.

Chandler, W. K., Hodgkin, A. L., and Meves, H. (1965). The effect of changing the internal solution on sodium inactivation and related phenomena in giant axons. Journal of Physiology, 180, 821-836.

Chandler, W. K., and Meves, H. (1965). Voltage clamp experiments on internally perfused giant axons. Journal of Physiology, 180, 788-820.

Conway, B. E. (1952). Electrochemical Data. Elsevier Publishing Company: Amsterdam.

Fieve, R. R., Meltzer, H. L., Dunner, D., Levitt, M., Mendlewicz, J., and Thomas, Ann. (1973). Rubidium: biochemical, behavioral and metabolic studies in humans. American Journal of Psychiatry, 130, 55-61.

Keynes, R. D., and Swan, R. C. (1959). The permeability of frog muscle fibres to lithium ions. Journal of Physiology, 147, 626-638.

Meltzer, H. L., Taylor, R. M., Platman, S. R., and Fieve, R. R. (1969). Rubidium: a potential modifier of affect and behaviour. Nature, 223, 321-322.

Meltzer, H. L., and Fieve, R. R. (1975). Current Developments in Psychopharmacology. Spectrum Publications: New York.

Paschalis, C., Jenner, F. A., and Lee, C. R. (1978). The effects of rubidium chloride on the course of manic-depressive illness. Journal of Royal Society of Medicine, 71, 343-352.

Schildkraut, J. J., Schanberg, S. M., Breeze, G. R. and Kopin, I. J. (1967). Norepinephrine metabolism and drugs used in the affective disorders. American Journal of Psychiatry, 124, 600-608.

Stolk, J. M., Conner, R. L., and Barchas, J. D. (1971). Rubidium induced increase in shock elicited agression in rats. Psychopharmacologie, 22, 250-260. 